\title{
الاستشراق والاستغراب
}

دكتور/ هـاشسم أبو المسعن على (1)

\begin{tabular}{|c|c|c|}
\hline الصفحــة & العنـــــــوان & f \\
\hline r & 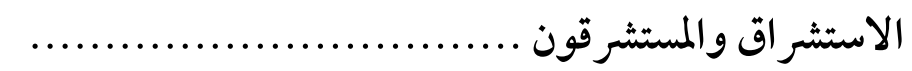 & 1 \\
\hline r & تعريف الاستشراق ................................. & r \\
\hline$\varepsilon$ & 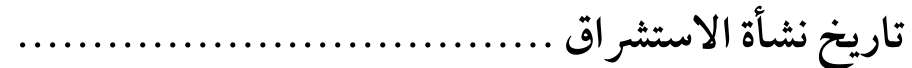 & r \\
\hline$\bullet$ & الاستشر اق .................................................... & $\varepsilon$ \\
\hline 7 & 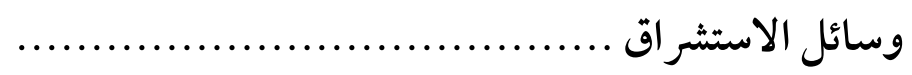 & $\bullet$ \\
\hline V & 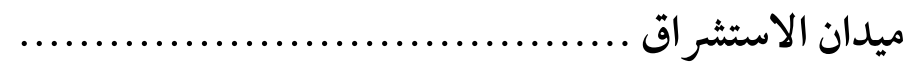 & Y \\
\hline V & 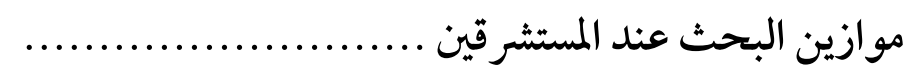 & V \\
\hline V & المر أة المسلمة فى الكتابات الاستشر اقية .................... & $\wedge$ \\
\hline$\Lambda$ & الأدب العربى الحلديث فى كتابات المستشرقين .................... & 9 \\
\hline$\wedge$ & 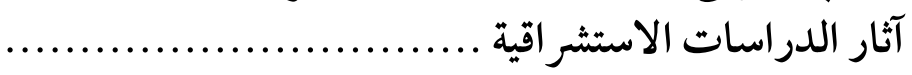 & 1. \\
\hline ir & 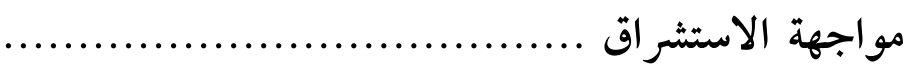 & 11 \\
\hline 10 & ..................... & ir \\
\hline 17 & 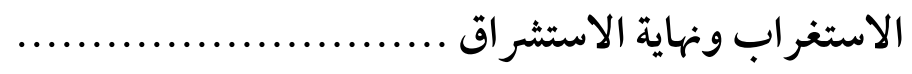 & ir \\
\hline 11 & & $1 \varepsilon$ \\
\hline
\end{tabular}

(1 ) كلية دار العلوم - جامعة المنيا

DOCTOR16671@GMAIL.COM 


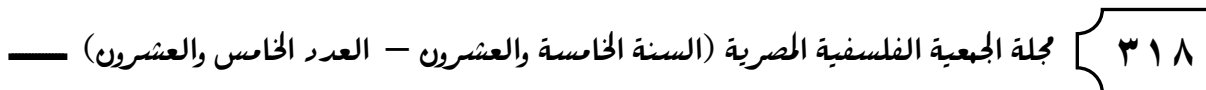

\section{مقدمـــة}

\section{الاستشراق والمستشرقون :}

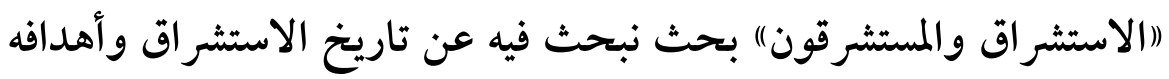

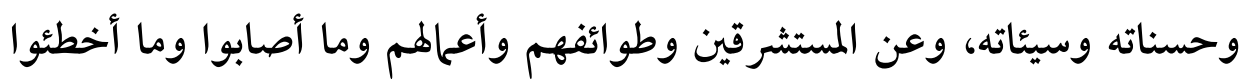

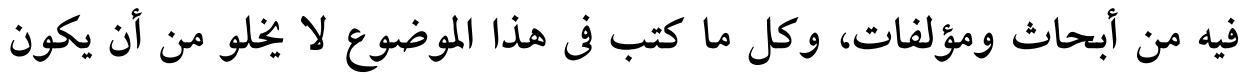

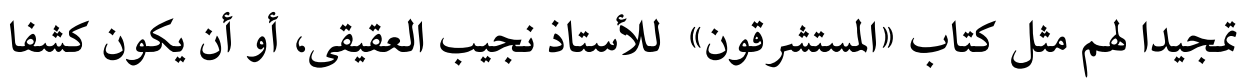

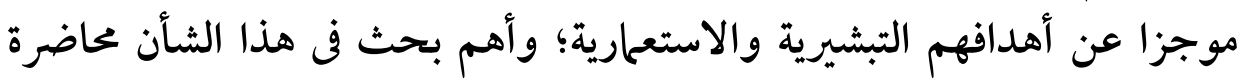

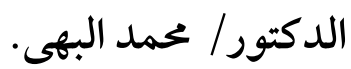

وقد أفرط منا أناس فى الثقة بهم والاعتهاد عليهم والثناء المطلق على جهودهم

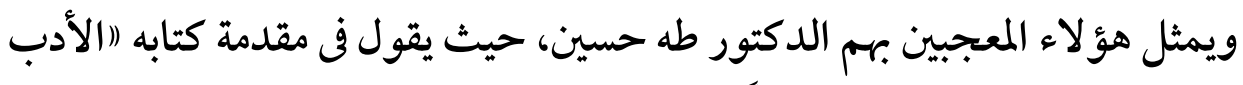

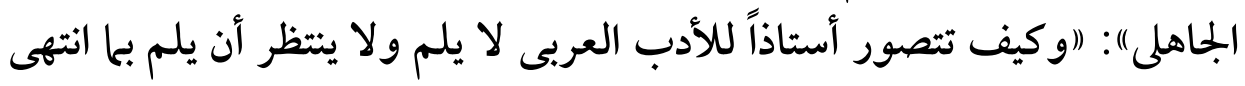

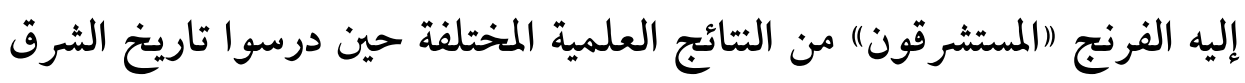

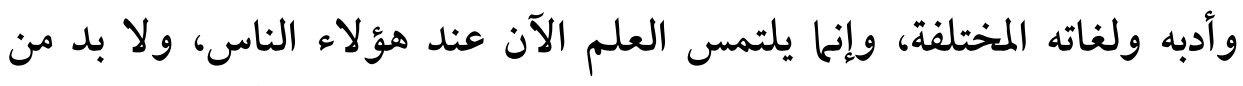

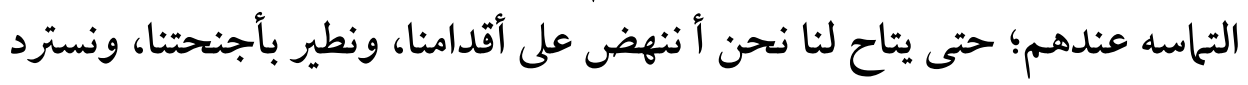

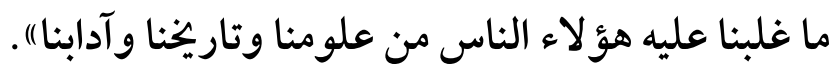

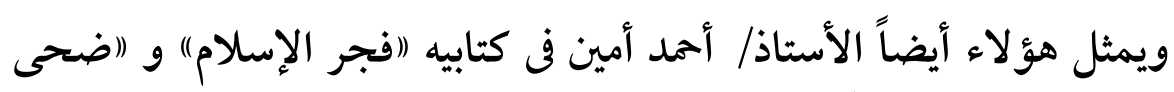

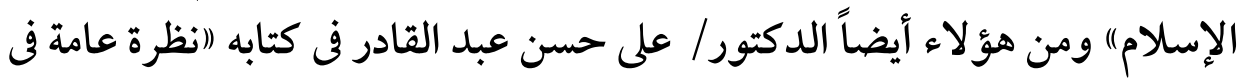

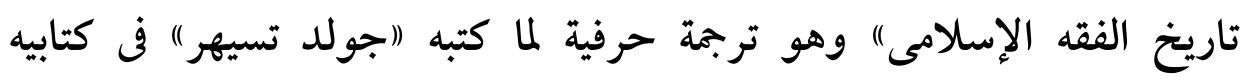
("دراسات إسلامية)) و ("العقيدة والشريعة في الإسلام)" .

ويقابل هذا الاتجاه المفرط فى الثقة ببحوث المستشرقين لتجاه يجمل على إنى

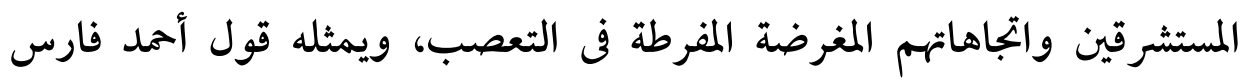
الشدياق فى كتابه (اذيل الفارياق)" 
والحق أن كلا من الثناء المطلق والتحامل المطلق يتنافى مع الحقيقة التاريخية

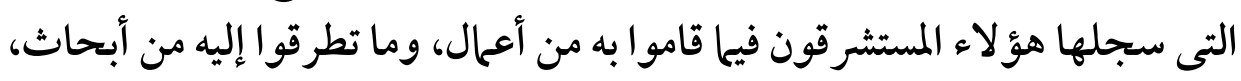

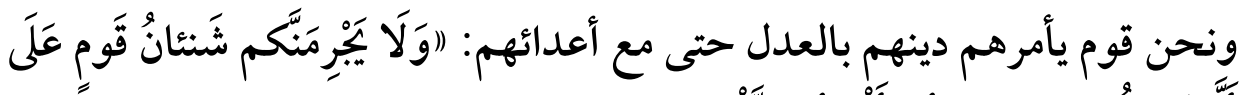

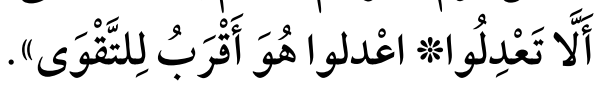

\section{أولاً: الاستشــــراق}

\section{تعريف الاستشـراق:}

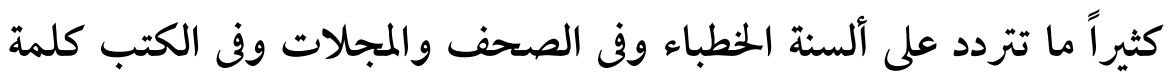

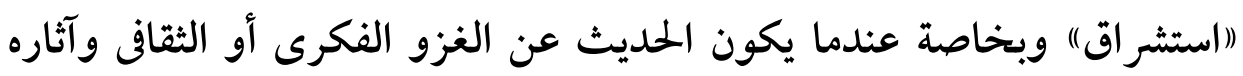

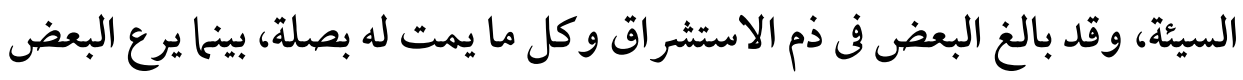

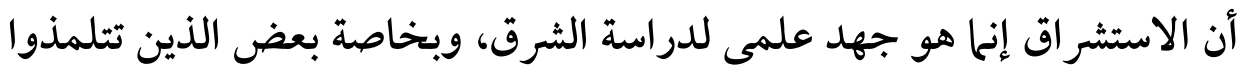

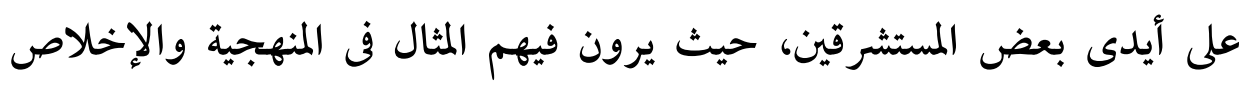
والدقة، فما معنى هذه الكلمة؟ بعض المستشرين

يمكن أن نبدأ بتعريفات المستشرقين أنفسهم لهذا المصطلح فهم أصحابه، ومن هؤلاء المستشرقين "رودى بارت) حيث يقول:

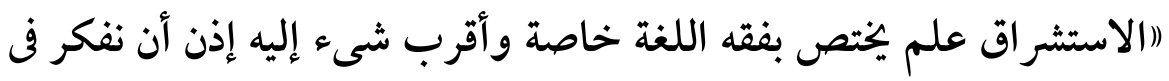

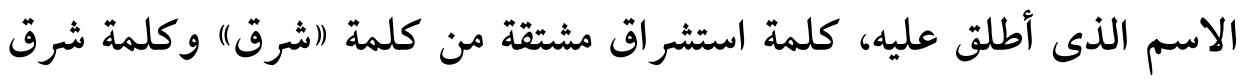

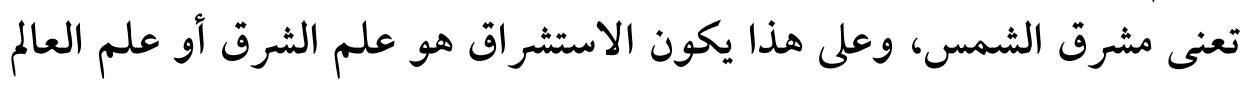
الشرقى. تعنى

ويعتمد المستشرق الإنجليزى (آربرى") تعريف قاموس (أكسفورد) الذى آلئ

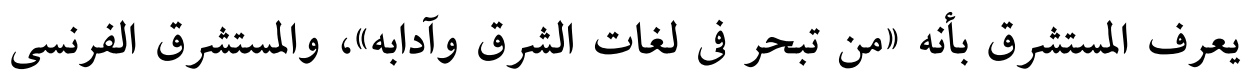

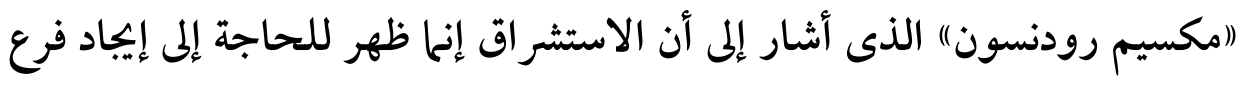




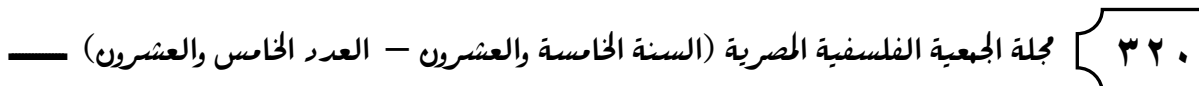

متخصص من فروع المعرفة لدراسة الثرق (ويضيف بأن الحاجة كانت ماسة لوجود متخصصين للقيام على إنشاء المجلات والجمعيات والأقسام العلمية) ). ولو انتقلنا إلى العرب والمسلمين الذين تناولوا هذا المصطلح نجد أن "(إدوارد

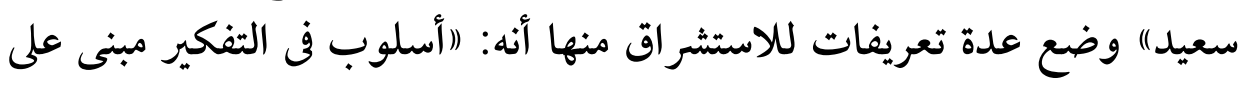

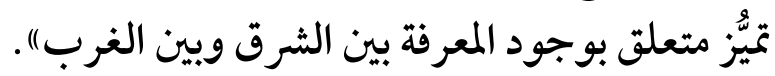

ويضيف (سعيد) بأن الاستشراق مجرد موضوع سياسى أو حقل بحثى ينعكس

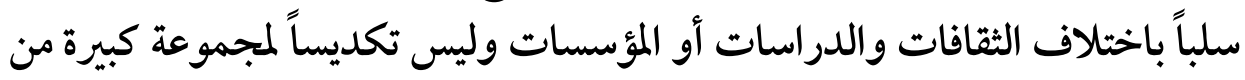
النصوص حول الشرق ... إنه بالتالى توزيع للوعى الجغرافى إلى نصوص بمالية وعلمية واقتصادية واجتحاعية وفى فقه اللغة) )

وفى موضوع آخر يعرف سعيد الاستشراق بأنه (المجال المعرفى أو العلم الذى يتوصل به إلى الشرق بصورة منظمة كموضوع للتعلم و الاكتشاف و التطبيق" . ويقول فى موضع آخر إن الاستشراق: (انوع من الإسقاط الغربى على الشرق وإر ادة حكى الغرب بالشرق" .

لقد قدم أحمد عبد الحميد غراب ججموعة من التعريفات للاستشراق استناداً

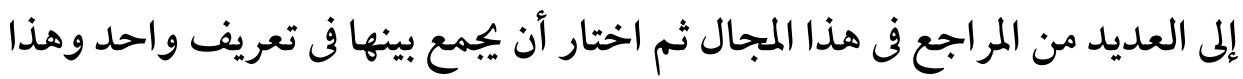
التعريف هو: "هو دراسات أكاديمية يقوم بها غربيون كافرون - من أهل الكتاب بوجه خاص - للإسلام والمسلمين، من شتى الجموانب: عقيدة، وشريعة، وثقافة، وحضارة، وتاريخا، ونظلا وثروات وإمكانات .... بهدف تشويه الإسلام ومحاولة

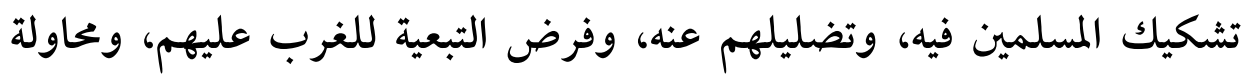
تبرير هذه التبعية بدراسات ونظريات تدعى العلمية والموضوعية، وتزعم التفوق

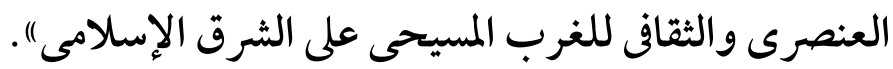


ومن خلال متابعة للاستشراق فإننا يمكن أن نقول إن الاستشراق هو كل ما يصدر عن الغربيين من أوربيين وأمريكيين من دراسات أكاديمية تتناول قضايا الإسلام والمسلمين فى العقيدة، والثريعة، والاجتحاع والسياسة أو الفكر أو الفن.

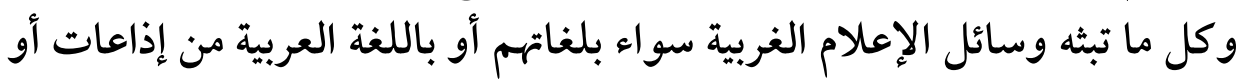

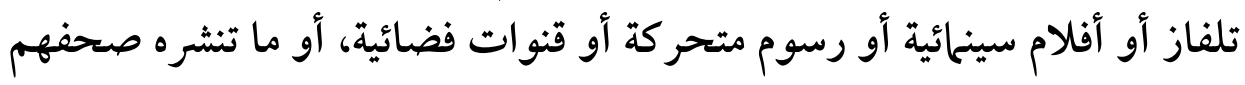
من كتابات تتناول المسلمين وقضاياهم.

ويمكننا أن نلحق بالاستشراق ما يكتبه النصارى العرب من أقباط ومارونيين وغيرهم من ينظر إلى الإسلام من خلال المنظار الغربى. وأيضاً ما ينشره الباحثون المسلمون الذين تتلمذوا على أيدى المستشرقين وتبنوا كثيراً من أفكار المستشرقين.

نشـأة الاستشــــاق

اختلف الباحثون فى نشأة الاستشراق فى تحديد سنة معينة أو فترة معينة لنشأة الاستشراق، فيرى البعض أن الاستشراق ظهر مع ظهور الإسلام فى أول لقاء بين

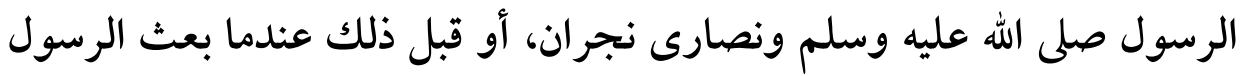

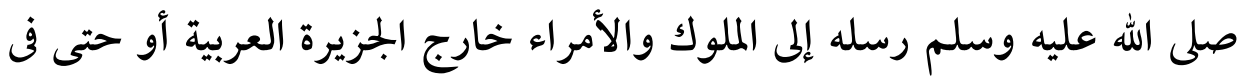

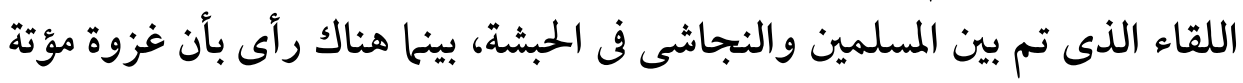
والتى كانت أول احتكاك عسكرى تعد من البدايات للاستشر اق.

ويرى آخرون أن أول اهتحام بالإسلام والرد عليه بدأ مع يوحنا الدمشقى وكتابه الذى حاول فيه أن يوضح للنصارى كيف يجادلون المسلمين. ويرى آخرون أن الحروب الصليبية هى بداية الاحتكاك الفعلى بين المسلمين

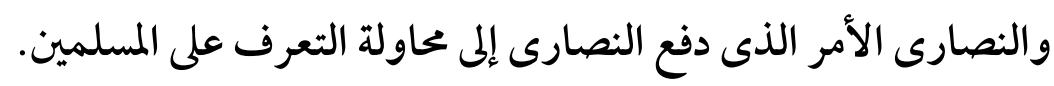




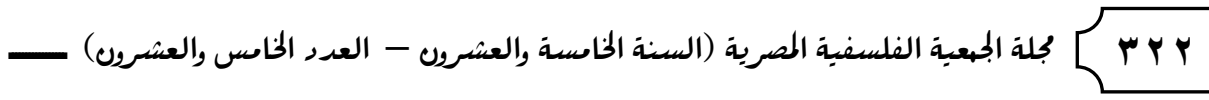

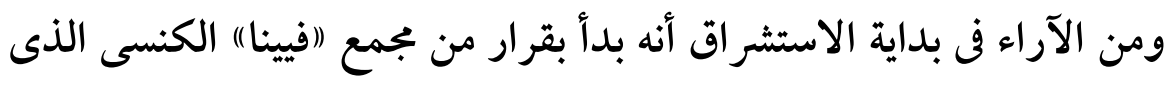

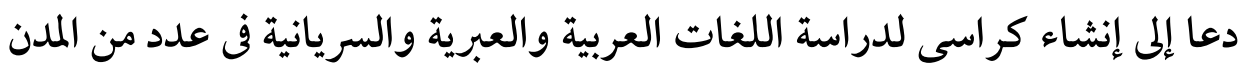
الأوربية وثمة رأى له عدد من المؤيدين أن احتكاك النصارى المسلمين في الأندلس الماء هو الانطلاقة الحقيقية لمعرفة النصارى بالمسلمين والاهتحام بالعلوم الإسلامية، ويميل إلى هذا الر أى بعض رواد البحث في الاستشراق من المسلمين ومنهم الشيخ الدكتور مصطفى السباعى.

ولا شك أن هذه البدايات لا تعد البداية الحقيقية للاستشر اق، وإنها تعد هذه

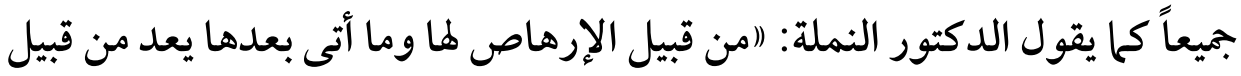
تعميق الفكرة، و التوسع فيها وشد الانتباه إليها) .

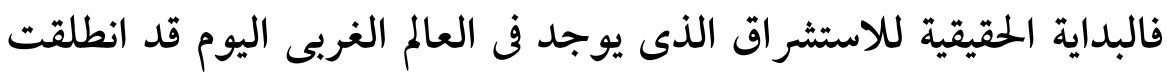

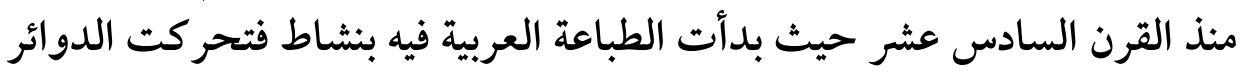
العلمية وأخذت تصدر كتاباً بعد الآخر ") .

ثم ازداد النشاط الاستشر اقى بعد تأسيس كراسى للغة العربية فى عدد من

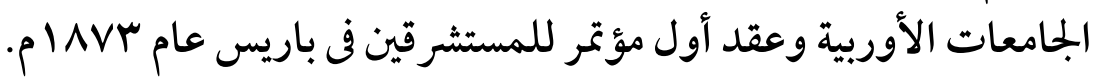

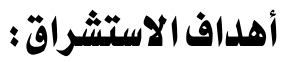

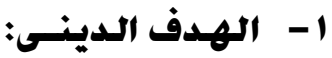

غاية المدف الدينى هى معرفة الإسلام لمحاربته وتشويهه وإبعاد النصارى عنه وقد اتخذ النصارى المعرفة بالإسلام وسيلة لحملات التنصير التى انطلقت إلى البلاد

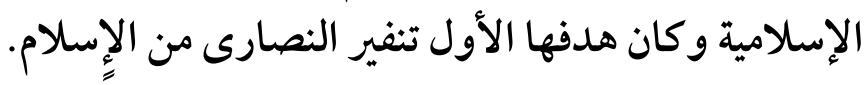

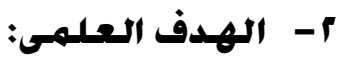

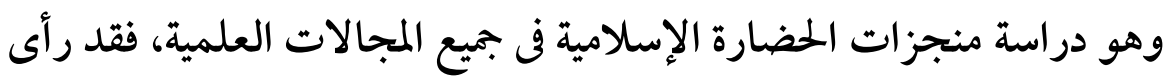

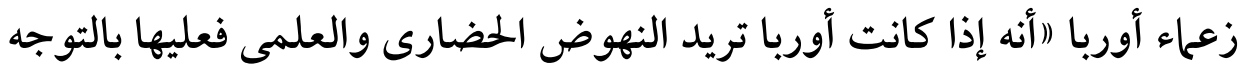
إلى بو اطن العلوم تدرس لغاته وآدابه وحضار اته ). . 


\section{" - الهدف الاقتصسادى التجمارى:}

عندما بدأت أوربا نهضتها العلمية والصناعية والحضارية و كانت فى حاجة إلى المواد الأولية الخام لتغذية مصانعها، كما أنهم أصبحوا بحاجة إلى اسواق تجارية

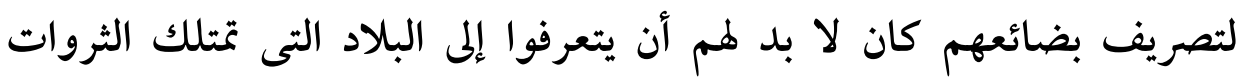

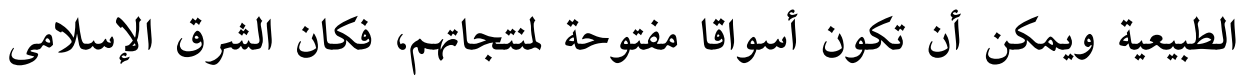

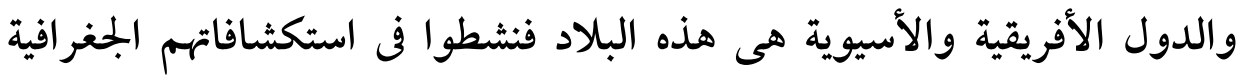
ودر اساتهم الاجتهاعية و اللغوية والثقافية وغيرها.

\section{ع- الهدف السيياسـ الاستعمهارى:}

لقد خدم الاستشراق الأهداف السياسية الاستعحارية للدول الغربية فقد سار

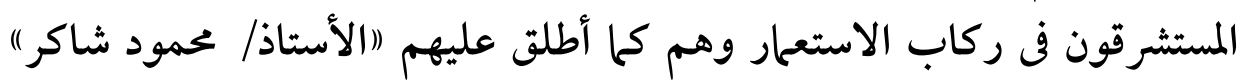
حملة هموم الثمال المسيحى فقدموا معلومات موسعة ومفصلة عن الدول التى رغبت الدول الغربية فى استعجارها والاستيلاء على ثرواتها وخير اتها.

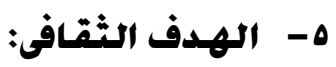

نشر الثقافة الغربية انطلاقا من النظرة الاستعلائية التى ينظر بها إلى الشعوب

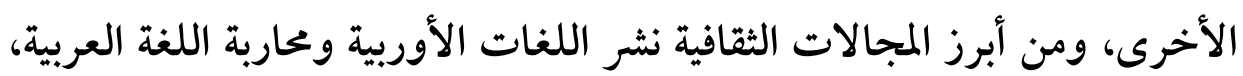
وصبخ البلاد العربية بالطابع الثقافى الغربى. وقد حرص الغرب على الغزو الثقافى من خلال التغريب الفكرى بعدة طرق

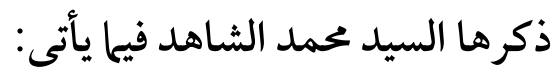
1 - التعليم من حيث المنهج ومن حيث المادة العلمية. ץ - وفى بجال الإعلام تُستغل كل وسائل الإعلام المتاحة وخاصة أفلام السينما و التلفاز ("تأثير غير مباشر ) . 


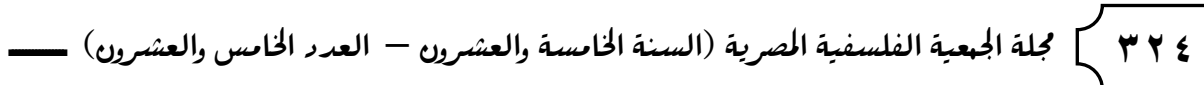

وظهر الهدف الثقافى من خلال الدعوة إلى العامية ومحاربة الفصحى والحداثة

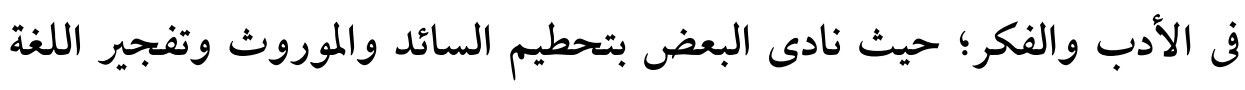
وغير ذلك من الدعوات.

\section{وسائل المستشرقيز لتحقيق أهدافهم:}

1 - تأليف الكتب فى موضوعات خختلفة عن الإسلام واتجاهاته ورسوله وقر آنه. r - أصدر المجلات الخاصة ببحوثهم حول الإسالام بلاده وشعوبه.

r- إرساليات التبشير إلى العالم الإسلامى لتزاول أعحالا إنسانية فى الظاهر

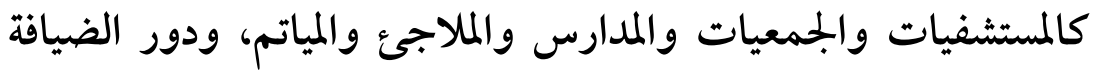
كجمعية الشبان المسيحية. ع - إلقاء المحاضرات في الجامعات والجمعيات العلمية. ه- مقالات في الصحف المحلية عندهم، فقد استطاعوا شراء عدد من الصحف المحلية فى بلادنا.

ج- عقد المؤتمرات لإحكام خططهم فى الحقيقة وبحوث عامة فى الظاهر منذ

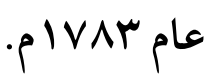
- - إنشاء الموسوعة (دائرة المعارف الإسلامية)) وفى هذه الموسوعة التى حُشد

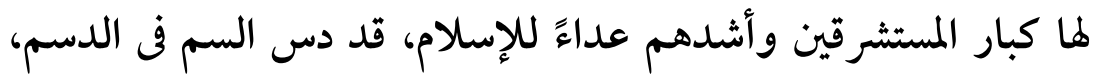
وملئت بالأباطيل عن الإسلام وما يتعلق به.

ميلدان الاستشراق:

بدأ الاستشراق بدراسة اللغة العربية والإسلام وانتهى - بعد التوسع الاستعلارى فى الشرق - إلى دراسة جميع ديانات الشرق وعاداته وحضاراته وجغر افية وتقاليده و أشهر لغاته. 


\section{موازين البحث عند المستشرقين :}

يضعون في أذهانهم فكرة معينة يريدون تصيد الأدلة لإثباتها، وحين يبحثون

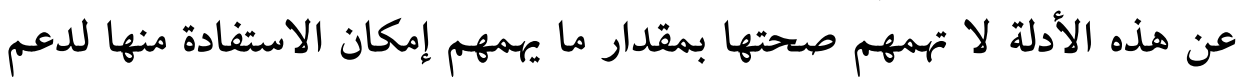
آرائهم الشخصية، وكثيرا ما يستنبطون الأمر الكلى من حادثة جزئية، ومن هنا يقعون فى مفارقات عجيبة لولا الهوى والغرض لبرئو ا بأنفسهم عنها.

\section{المرأة المسلمة فى الكتابات الاستشراقية:}

الدراسات الاستشر اقية حول المرأة المسلمة والاهتحام بالأوضاع الاجتماعية من الأمور التى تهتم بها الدوائر الاستشر اقية وتجند لما طاقات كبيرة، ولئن بدأت هذه الدراسات في الحديث عن المصادر الإسلامية وموقفها من المرأة والعلاقة بين الرجل والمرأة وقضايا الأسرة لكنها أخذت تزداد عمقا وتخصصا دون أن تترك هذه المهن المجالات الفقيه والشرعية.

وقد أضيف إلى الدراسات الاستشراقية النشاطات التى تقوم بها الباحثات العربيات والمسلمات بالإضافة إلى الكتابات الادبية التى تعد مصدرا مها فى النظرة

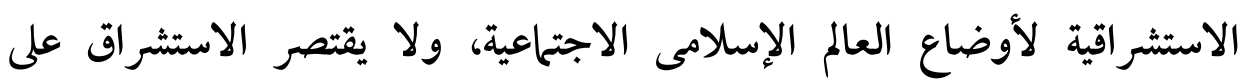
الدراسات الأكاديمية والبحوث الميدانية فإن الغرب حريص على التأثير فى العالم كله الإنه ونشر ثقافته وفكره وقيمه من خلال وسائل الإعلام والمؤتمرات الدولية الإمية التى

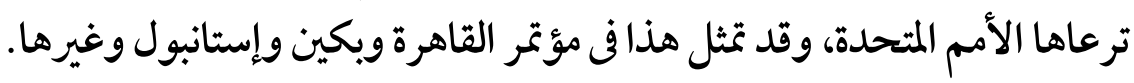
فهل يأخذ المسلمون زمام المبادرة في دراسة أنفسهم وفق المعايير والقيم الإسلامية المستندة إلى الكتاب والسنة؟ فنمثل أنفسنا أمام أنفسنا ونعرف عيوبنا قبل أن يوجه إلينا الآخرون سهام الانتقاد ولعلنا أيضا نصل إلى دراسة الغرب الإبـ

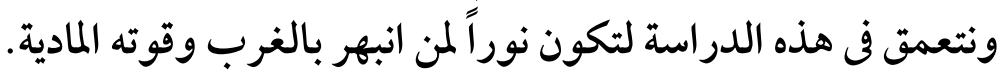




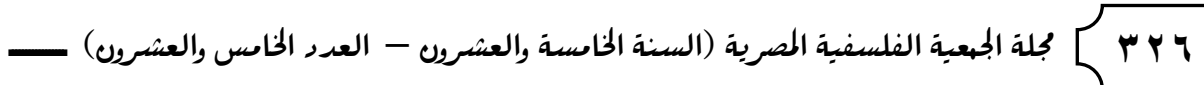

\section{الأدب العربى الحليث فى كتابات المستشرقين}

اهتم الاستشراق المعاصر بالأدب العربى الحديث وهذا الاهتحام موجود ولكنه

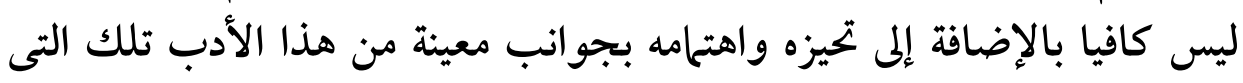

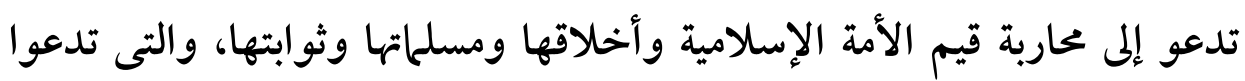
تشويه التاريخ الإسلامى كحا في كتابات جورج زيدان وأمثاله، واهتحامهم بلغة الأدب والاستمرار فى الدعوة إلى العامية وإلى الشعر الحر أو المثثور وغير ذلك من فئ

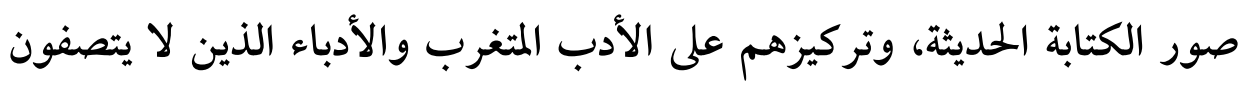
بالأصالة والمحافظة على قيم الأمة الإسالامية.

\section{آثار الدراسات الاستشراقية:}

قدم الاستشراق خدمة كبيرة للغرب النصرانى فى خدمة أهدافه التى قام من أجلها ولكنه في الوقت نفسه أثر تأثيرات سلبية في العالم الإسلامى فى المجحالات

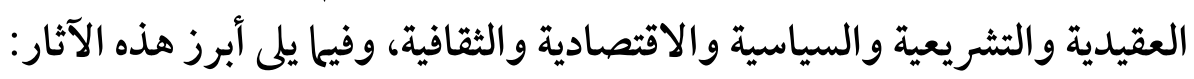

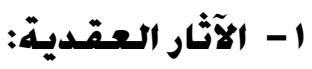

ظهور تيار من المفكرين والعلم)ء والسياسيين وحتى الناس العاديين أو العامة

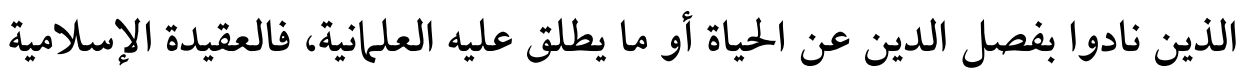

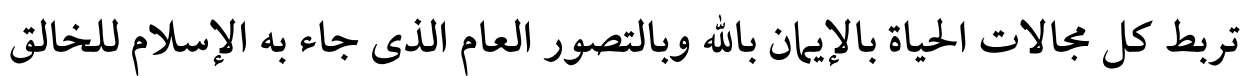

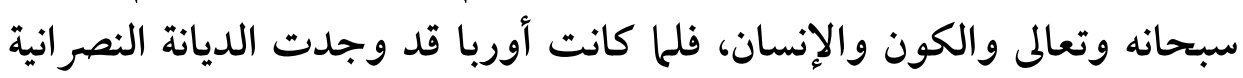

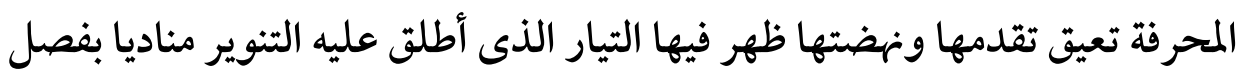

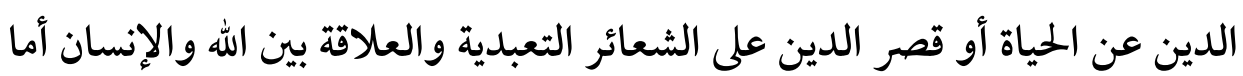
شئون الحياة الأخرى فلا علاقة للدين بها.

ومن تأثير الاستشراق فى المجال العقدى الاهتحام المبالغ فيه بالصوفية وبخاصة تلك التى ابتعدت عن الكتاب والسنة فنجدهم يجعلون لـ (ابن عربى)" مكانة 
خاصة فى النشاطات الاستشر اقية والاهتحام بالفرق المنحرفة كالر افضة والاسماعيلية وغيرها من الفرق.

\section{r - الآثار الاجتمهاعينة:}

تعد الآثار الاجتحاعية من أخطر الآثار التى مازال الاستشراق حريصا على تحقيقها في العالم الإسلامى ومعرفتها معرفة وثيقة حتى يمكنهم أن يؤثروا فيها

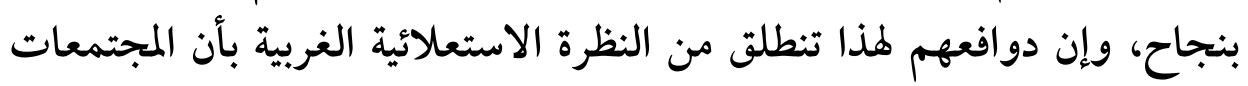
الغربية وما ساد فيها من فلسفات ونظريات هى المجتمعات الأرقى فى العالم، وقد تمكن الاستعجار بالتعاون مع الاستشراق فى إحداث تغيرات اجتهاعية كبيرة في البلاد التى وقعت تحت الاحتلال الغربى.

فنى الجززائر مثلا حطم الاستعحار الملكيات الجماعية أو المشاعة للأرض وذلك لتمزيق شمل القبائل التى كانت تعيش فى جو من الانسجام والوئام. فقد تعاون الاستشراق والاستعهار على إحداث نزاعات بين أبناء البلاد

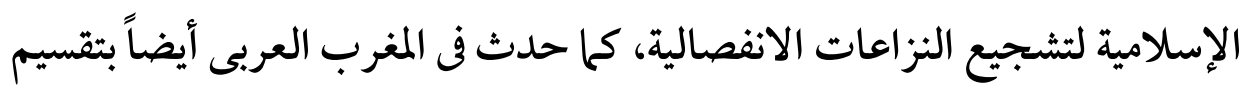

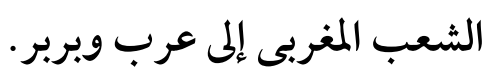

ومن الجوانب الاجتماعية التى عمل فيها الاستشراق على التأثير فى المجتمعات

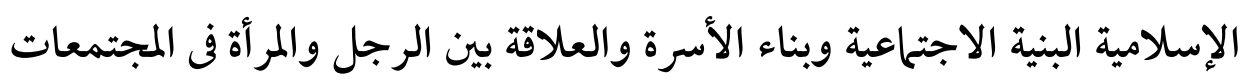
الإسالامية.

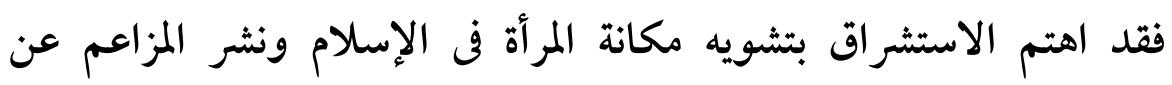

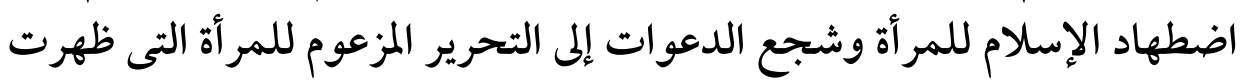

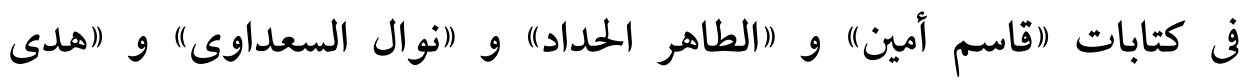

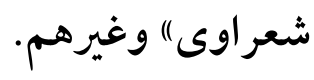




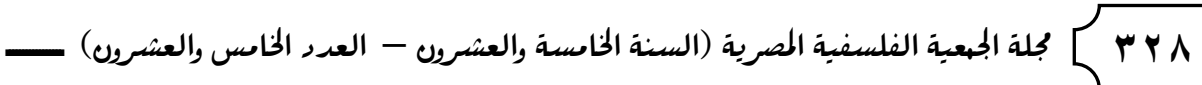

ويرى الدكتور محمد خليفة أن موقف الاستشراق من المر أة المسلمة من وقوعه "اتحت تأثير وضع المرأة الغربية إنها نموذج يجب أن يحتذى به، وأن ما حققته من مساواة - فى نظرهم - وحقوق يجب أن تتسع لتشمل المرأة المسلمة والمرأة الشرقية

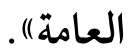

ويضيف خليفة بأن الاستشراق يسعى (إلى تقويض وضع المر أة المسلمة داخل الأسرة على التمرد على النظام والخروج باسم الحرية وتصوير وضع المرأة المسلمة تصوير ا مزيفا لا يعكس الحقيقة) ).

ويقوم الاستشراق الإعلامى بدور بارز فى الترويج للفكر الغربى فى بجال المرأة من ذلك الصحافة الغربية والإذاعات الموجهة.

\section{س- الآثار السـياسية والاقتصسادية:}

يزعم الغربيون أن الديمقر اطية الغربية هى أفضل نظام توصل إليه البشر حتى

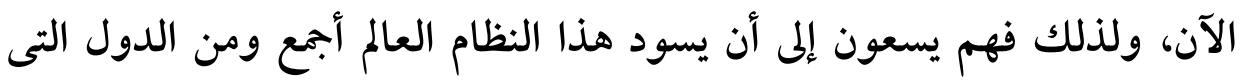
يريدون لنظامهم أن يسودها البلاد الإسلامية.

وقد سعوا إلى هذا من خلال عدة سبل، وأبرزها هو انتقاد النظام السياسى الإسلامى.

وقد ظهرت كتب كثيرة عن نظام الخلافة الإسلامى وافتروا على الخلفاء الر اشدين بزعمهم أن وصول الصديق وعمر بن الخطان رضى الله عنها إلى الخلافة كان نتيجة لمؤامرة بين الاثنين وكتب مستشرقون آخرون زاعمين أن النئ النظام السياسى الإسامى نظام قائم على الاستبداد وفرض الخضوع والمذلة على الشعوب الخب الإسلامية بل بالغ (لويس)" فى جعل النظام السياسى الإسلامى يشبه النظام الشيوعى فى استبداده وطغيانه. 
وقد تأثرت بعض الدول العربية التى خضعت للاستعمار الغربى بالفكر

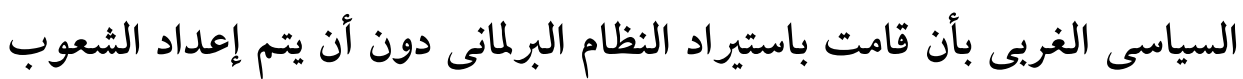

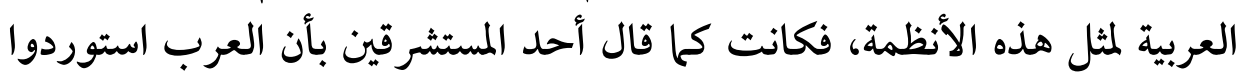
برانمات فعلية دون ورقة التعليمات.

أما في المجال الاقتصادى فإن الغرب سعى إلى نشر الفكر الاقتصادى الغربى الاشتراكى الرأسحالى وذلك بمحاربة النظام الاقتصادى الإسلامى، وكحا يقول (احممد خليفة)): (أن المستشرقين فى سعيهم للترويج للفكر الاقتصادى الغربى قاموا بإعادة تفسير التاريخ الاقتصادى الإسلامى من وجهة نظر الرأسمالية والشيوعية

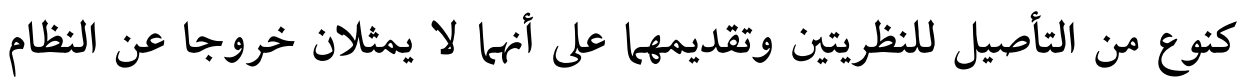

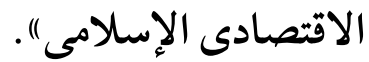

و كان من نتائج الترويج الاشتراكية والر أسمالية فى العالم الإسلامى أنه انقسم العالم الإسلامى على نفسه فأصبح قسم منهم يدور فى الفلك الشيوعى والقسم

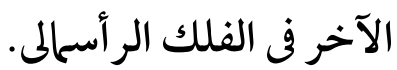

وكان من تأثير الاستشراق أيضا تشجيع الصناعة فى البلاد الإسلامية دون

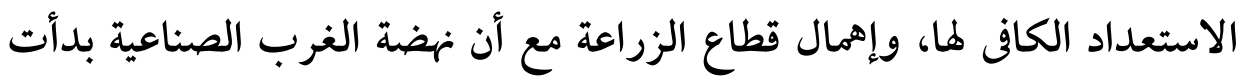
بالاهتحام بالزراعة.

\section{ع- الآثار الثقافية والفكرية:}

أصبحت المصادر الغربية تدخل فى التكوين الفكرى الثقافى لهذه الأمة سواء

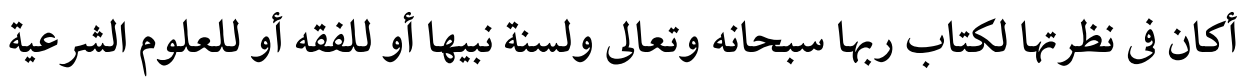
الأخرى، أو فى منهجية فهم هذه المصادر ومنهجية التعامل معها، كما أثر الفكر

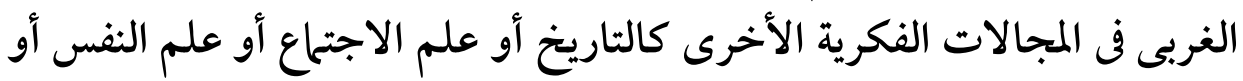
علم الإنسان أو غيرهم من العلوم. 


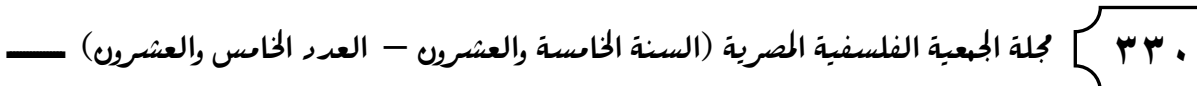

و كان للاستشراق دورا فى بجال الأدب شعراً ونثراً وقصةً، فقد استغلت هذه الوسائل فى نشر الفكر الغربى العلمانى وبخاصة عن طريت ما سمى "الحداثة" التى تدعو إلى تحطيم السائد والموروث وتفجير اللغة وتجاوز المقدس ونقد النصوص المقدسة.

وعن موقف العراقى من الاستشراق والمستشرقين يبدأ أولا بتعريف الاستشراق بأنه دراسة الغربيين لتاريخ الثرق أمهه ولغاته وآدابه وعلومه وعاداته ومعتقداته وأساطيره، فهو حركة علمية عنيت ولا تزال تعنى بدراسة الحضارة الشرقية من قبل باحثين ينتمون إلى حضارة أخرى لهم بناء شعورى شخالف لبناء الحضارة التى يدرسونها.

وإذا كان الهجوم على المستشرقين بحجة تمييزهم بين الجنس السامى (العربى) والجنس الآرى (الأوروبى) من بعض المفكرين، فنى العصر الحالى قد لا نجد قبولا حتى من جانب المستشرقين أنفسهم لمذه الفكرة أو النظرية، بل نجد ردودي ردوداً

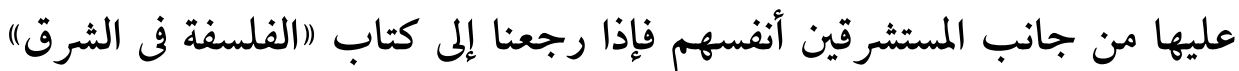

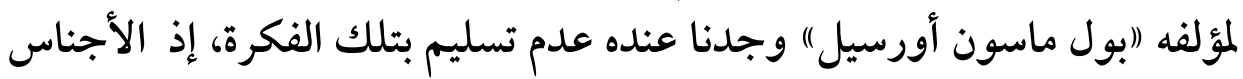

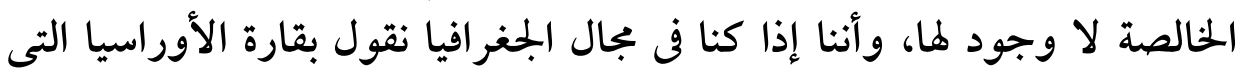
تجمع بين أوروبا وآسيا، فلا يصح إذن التفرقة بين عقلية هى وحدها لديها القدرة على الفكر الفلسفى وهى العقلية الآرية الأوروبية، وعقلية لا تستطيع بطبيعتها التفلسف وتقديم المذاهب الفلسفية وهى العقلية السامية العربية.

فقد ذهب بعض المستشرقين الغربيين إلى القول بقصور العقل العربى (السامى) وعجزه عن الإبداع وأن الإسلام يحارب العقل ويدعو إلى الجمود والتبعية والانقياد إلى تعاليم الله ورسوله، وبالتالى انعدام وجود فكر عربى فى المجالين الفلسفى و العلمى. 
وقد دافع العر اقى عن الاستشر اق لكن لم يكن دفاعه مطلقا أى لم يقبل كل ما

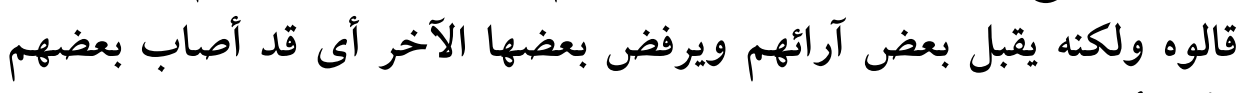
وأخطأ بعضهم.

وفى دفاعه عن الاستشراق والمستشرقين أو الفكر الغربى عموما يؤكد أن التأثر

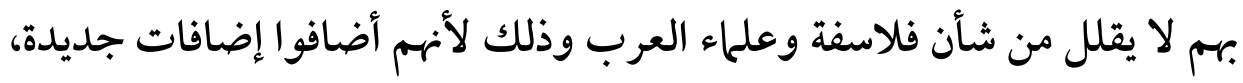

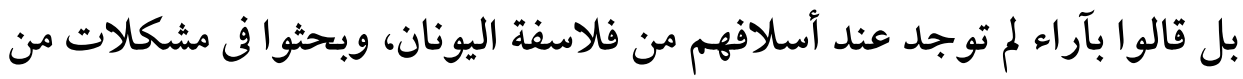

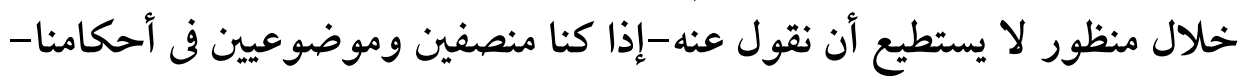

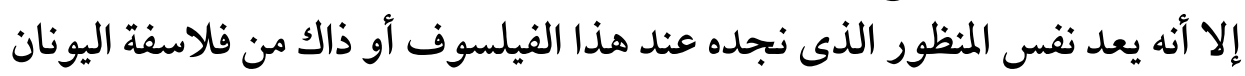
القدامى.

وعلى الرغم من دفاع العراقى عن الاستشراق، إلا أنه انتقد بعض المستشرقين

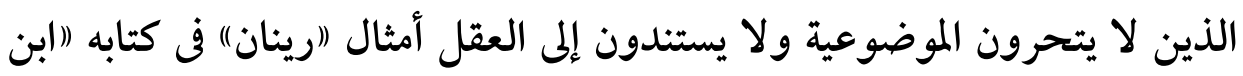

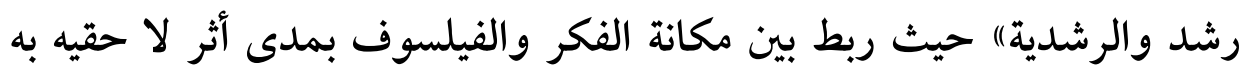

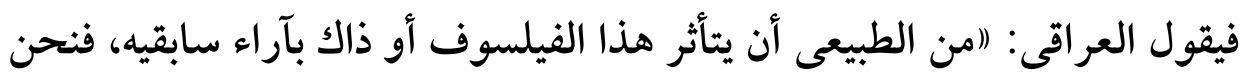

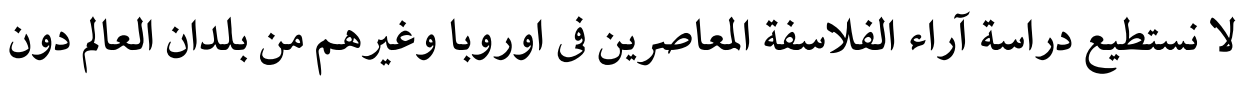

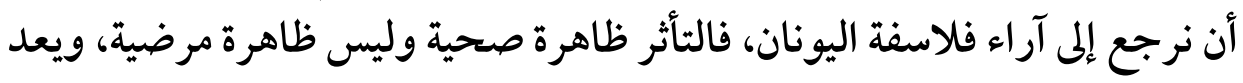
دليلا على ثقافة المفكر أو الأديب واطلاعه على المانى آراء السابقين.

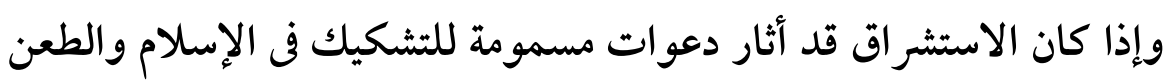

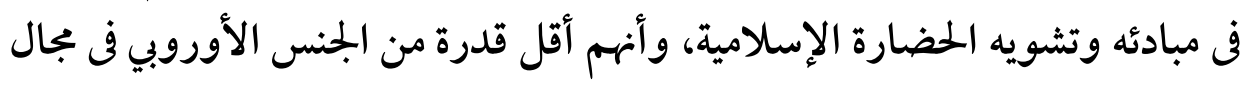

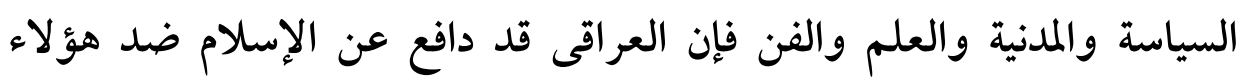

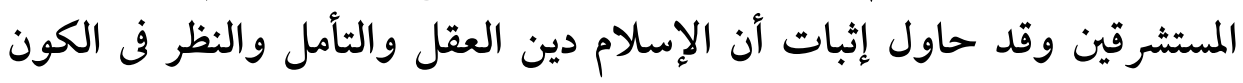

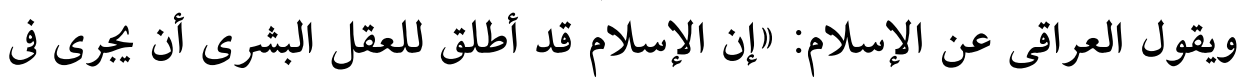

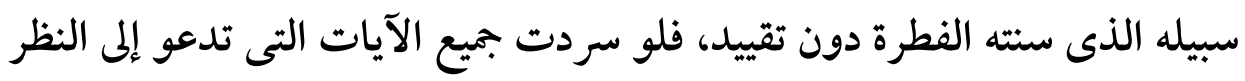




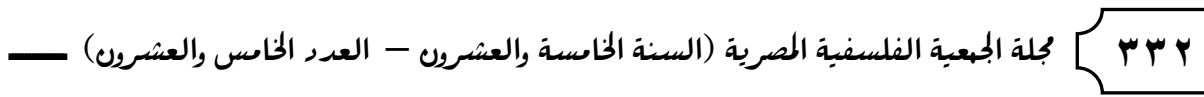

فى آيات الكون لأثيت بأكثر من ثلث القرآن، فالإسلام قد أطلق العنان للعقل، ولم يقيد العقل بكتاب، ولم يقف عند باب، ولم يطالبه فيه بحساب.

كما وجه العراقى نقده إلى بعض المستشرقين الذين يذهبون إلى أن الفرق الإسلامية هى التى يجب أن يبحث فيها عن الحر كة الفلسفية في الإسلام (كالقدرية والجبرية والأشعرية)، ولكن يخالفهم العراقى فى ذلك ويؤكد على أن منهج المتكلمين ليس بمنهج الفيلسوف الذى يبحث عن الحق لذاته، الحق فى نفسه، الحق جردد غاية التجريد، بل يدور منهجهم حول أسس برهانية، ولهذا لا يعدون فلاسفة، طالما أنهم تأثرو ابمجحال غير المجال الذى يجب ئب أن يبحث فيه الفيلسوف.

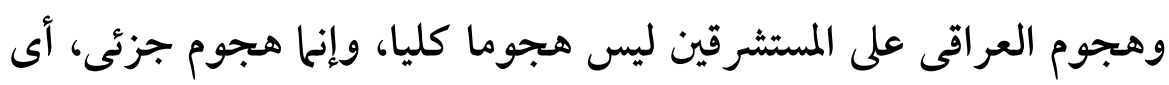
على بعضهم فقط، فللاستشراق أهمية كبرى، لذلك فإن الحملات التى شنها الناقدون المهاجمون على الاستشراق قد وصفها العراقى بأنها حملات مسعورة يحلو

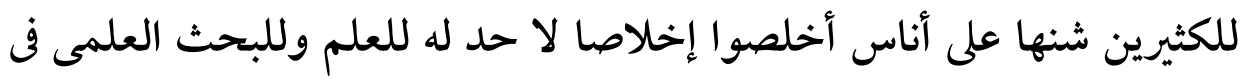
جال تحقيت التراث وإحيائه، وقدموا العديد من الأفكار البناءة والمفيدة غاية الفائدة، فقد تراكمت الدراسات الاستشر اقية وقوى نفوذها حتى صارت النخب

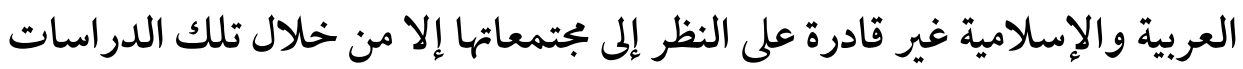
التى فرضت نفسها بسبب أسس الموضوعية فللاستشراق إيجابيات وسلبيات، فلا

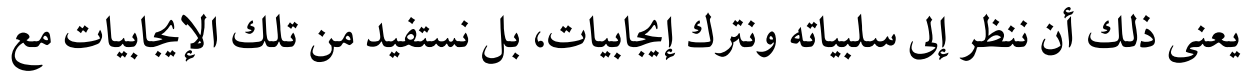
تصحيح نظرة المستشرقين إلى عالمنا العربى والإسلامى. فقد تناول المستشرقون تر اثنا بالكشف والجمع والصون والتقديم والفهرسة، وعمدوا إلى درسه وتحقيقه ونشره وترجمته و التصنيف فيه: فى منشئه وتأثره وتطوره

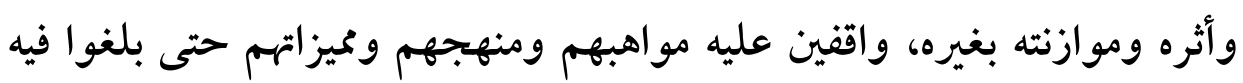
مبلغا عظيا من العمق والشمول. 
إن المستشرقين تناولوا في أبحاثهم ودراساتهم ومقالاتهم وكتبهم التراث

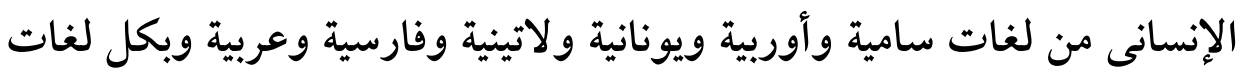

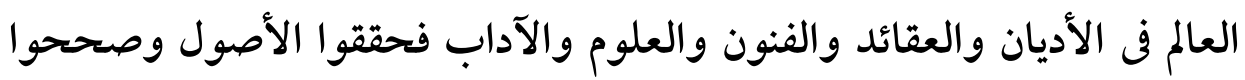

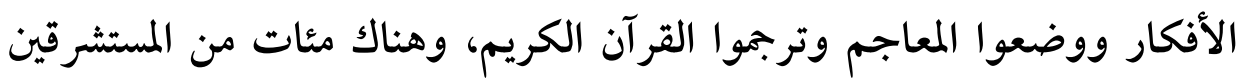

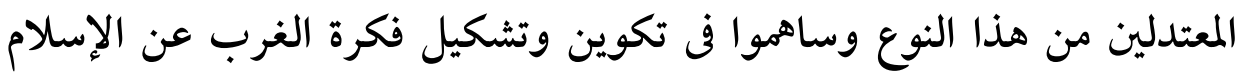
والشرق وبذلك لا يمكن إنكار الدور الذى لعبه المستشرقون في المحافظة على تراثنا وفكرنا العربى الإسلامى.

كما أن للاستثراق قيا متشعبة الأطر اف لا يمكن إنكار أية منها مطلقا، وقد إند

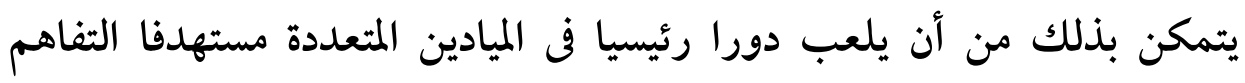

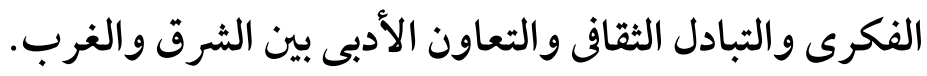

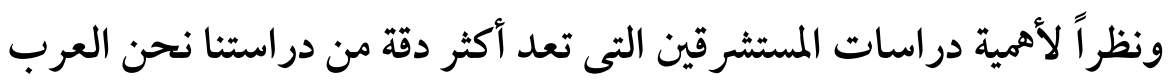

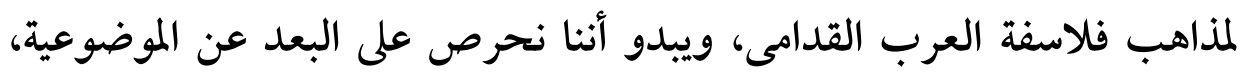

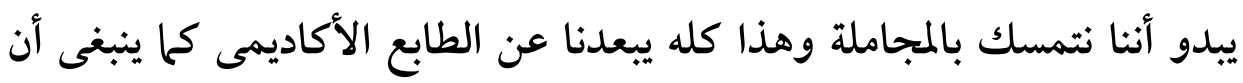
يكون.

فالمقارن بين الدراسات التى يقدمها نفر من المستثرقين لهذا المجال أو ذاك من

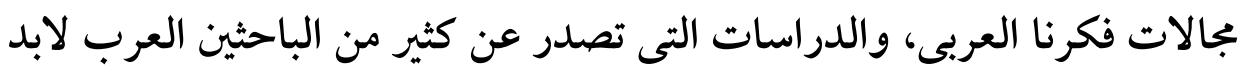

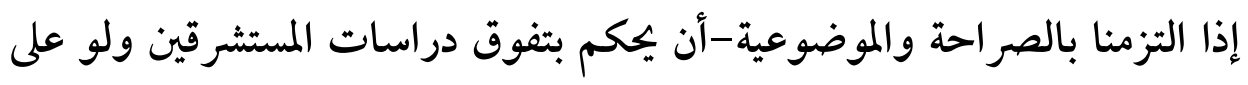

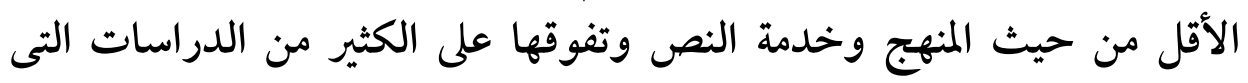

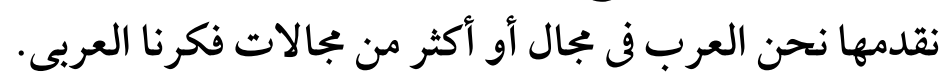

وإذا كان للاستشراق عناصر إيجابية، وعناصر سلبية فليس من الصعب

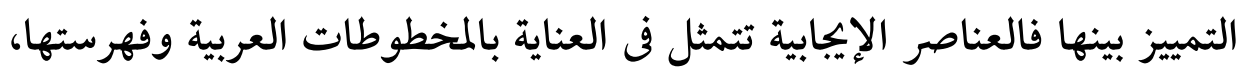

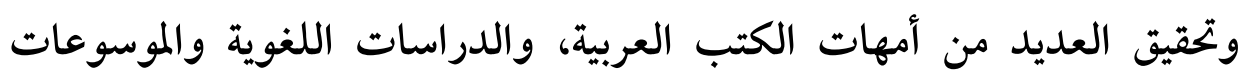

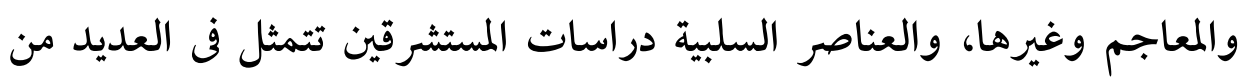




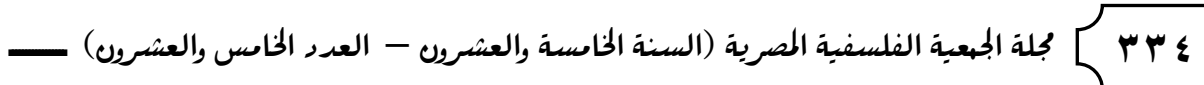

الدراسات والبحوث حول القرآن والسنة المحمدية وسيرة الرسول صلى الله عليه

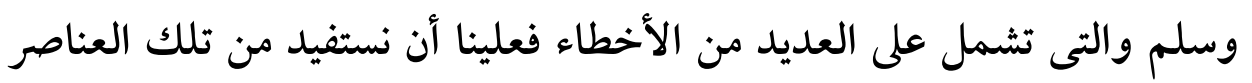
الإيجابية، وتصحيح الجموانب السلبية وما وقع فيه المستشرقون من أخطاء، وهذا يعنى التو اصل العلمى فى هذا المجحال.

\section{مواجهـــة الاستشــراقة}

وفيها يلى نقدم بعض الوسائل لمواجهة الاستشراق، فكا قال الدكتور/ أكرم

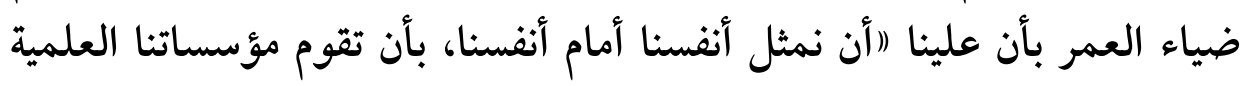
برسم الصورة الثقافية والتاريخية والعقدية لأمة الإسلام دون أن تخضع للأفكار

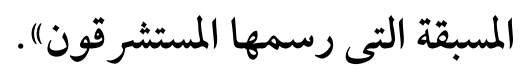

وهذا يعنى أن يقوم الدعاة والعلماء المسلمون بواجب الدعوة بنشر كل ما يتعلق بالإسلام فى شتى جوانب الحياة، وأن نسعى إلى تطبيق الإسلام التطبيق

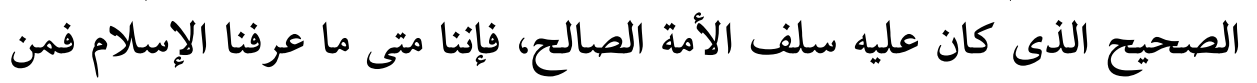
السهل أن نتعرف على الشبهات التى يثيرها الاستشراق ونستطيع أن نرد عليها. وثمة جانب آخر لمواجهة الاستشراق وهو أن ندرس الاستشراق من خلال

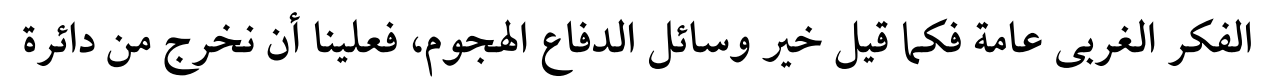
الدفاع التبريرى إلى الهجوم وهذا منهج قرآنى فى الجدال مع الأمم الأخرى

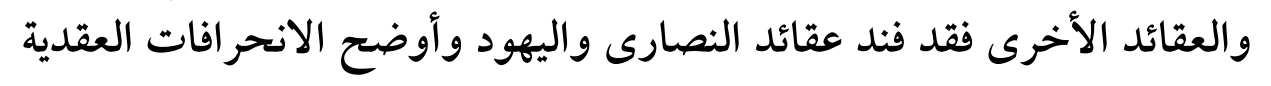
و الفكرية والاجتماعية التى كانوا يحارسونها.

كما أوضح انحر افات الجاهلية فى لا اعتقاد وفى الاجتحاع وفى الاقتصاد وفى الأخلاق. 
وعلينا أن نسعى إلى تشجيع الغربيين الذين يظهر فى دراساتهم بعض التوازن والاعتدال فى نشر إنتاجهم والترويج له، واستضافتهم فى العالم الإسلامى فى فئن

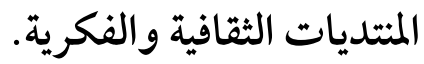

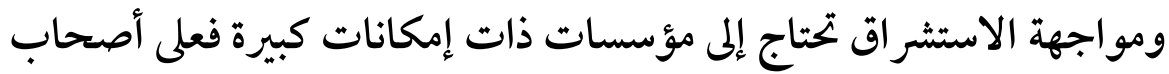

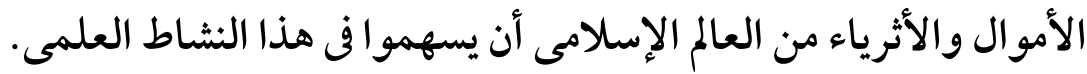
ومحاولة السيطرة على وسائل الإعلام بجا تبثه من فكر بخالف للإسلام وتشجيع العلماء والأدباء المسلمين على ممارسة دورهم في هذا الجانب.

\section{ثانيا : الاستفــراب}

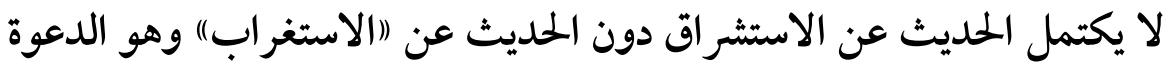

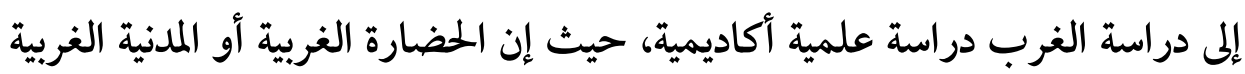
هى السائدة، وهى النى تملك القوة فى مختلف وجوهها من قوة عسكرية وإدارية وسياسية والتفوق العلمى والتفوق الثقنى، وتسيطر على وسائل الإعلام.

ولا بد لنا من التعمق فى دراسة هذه الحضارة لندرك كيف وصلت إلى أسباب

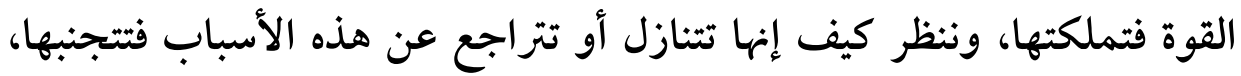

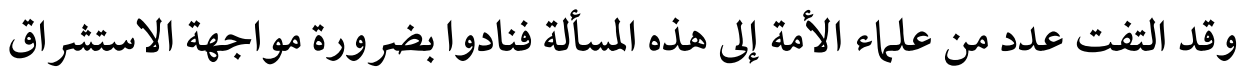

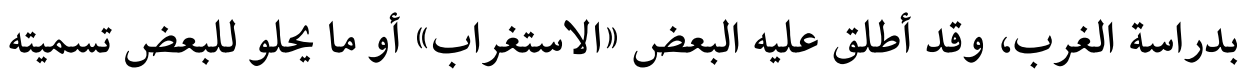

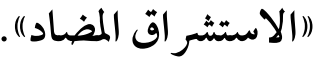

ومن هؤلاء العلماء الدكتور/ محمود حمدى زقزوق الذى كتب يقول: (اومن

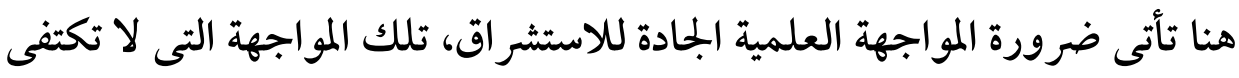

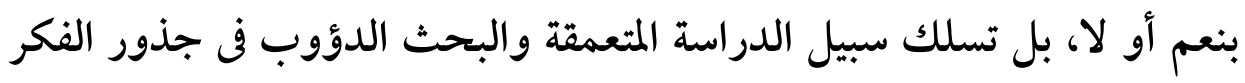

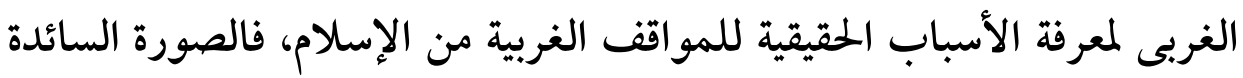




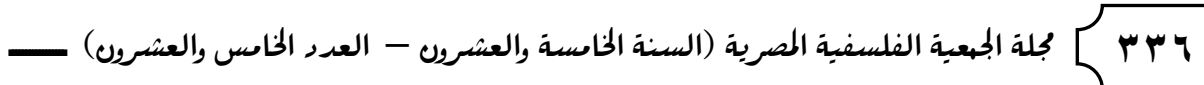

عن الإسلام فى الغرب ليست بحرد صورة وقتية عارضة، ولا هى بنت اليوم، وإنها هى صورة صاغتها قرون طويلة من الصراع الحضارى بين الإسلام والغرب. وهنا يلفت الدكتور/ زقزوق نظرنا إلى مسألة مهمة وهى ضرورة فهم جذور المواقف الأوربية من الإسلام، وليس الاكتفاء بظاهر أقوالهم، وهو الذى يجعلنا حين نرد على شبهاتهم وانتقاداتهم للإسالام فى المجالات المختلفة أن تكون لنا معرفة الإستة دقيقة بهم فتتحول من الدفاع إلى الهجوم" .

أما عن دراسة الغرب دراسة علمية حضارية فيقول الدكتور/ السيد الشاهد: (اكحا لا يكفى التنبيه إلى خطورة الاستشراق والمستشرقـين والنصارى والمنصرين،

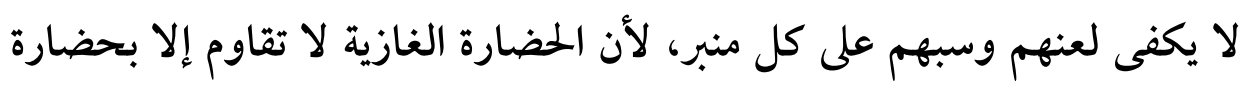
أقوى منها، علينا أن نبدأ بمعرفة واقعنا والاعتراف به وتحكي منديد إمكاناتنا بهدوء وتواضع.

علينا أن نبحث عن خخرج من موقفنا الضيق إلى موقع قوى مؤثر ولا يمكن

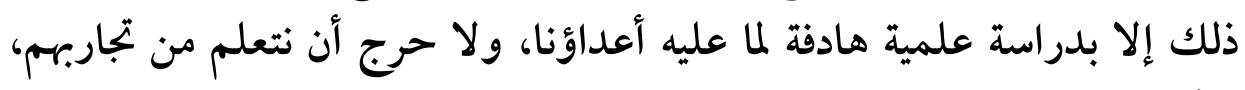

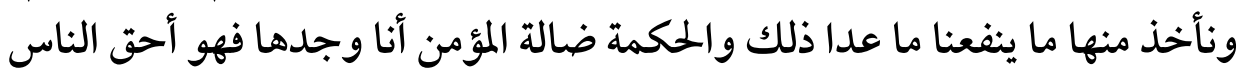
. (1)

ومع هذا الاتجاه القوى لأهمية دراسة الغرب فإن هناك من لا يعارض ما

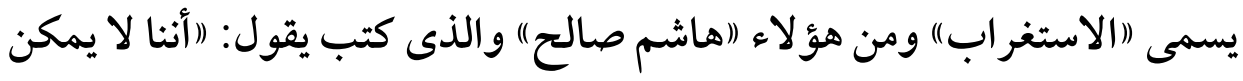

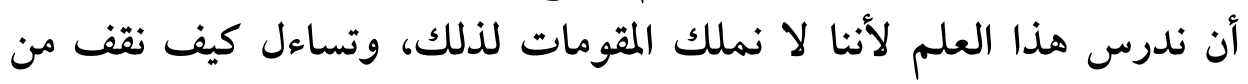

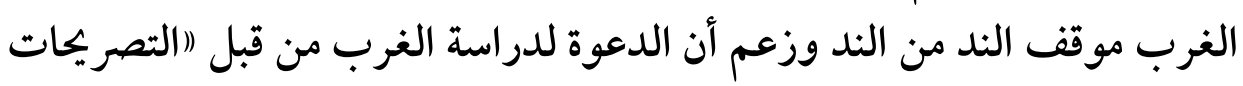
العنترية) ولكنه يدعو إلى ان تستمر فى دور التلميذ للغرب حتب حتى نستطيع أن نقوم بها

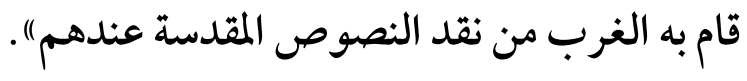
وليس ثمة من رد على مثل هذا الثثبيط إلا القول بأن هذه هى الروح الانهز امية. 


\section{الاستفراب ونهاية الاستشراق:}

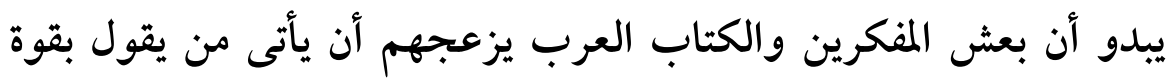

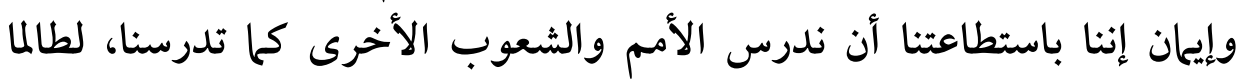

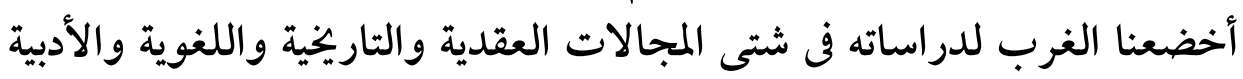

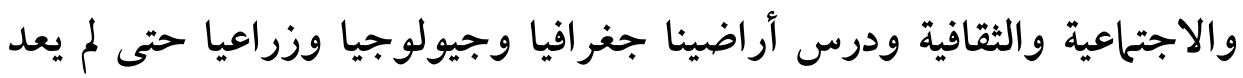

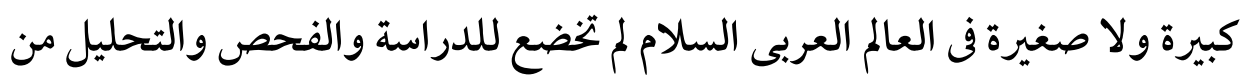
قبل الباحثين الغربيين.

لقد طالب الدكتور / حسن حنفى فى كتابه (مقدمة فى علم الاستغراب) أن نأخذ

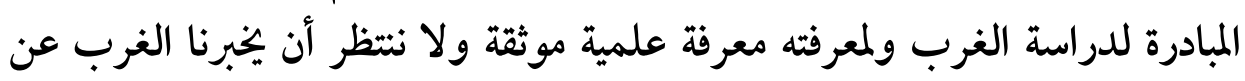

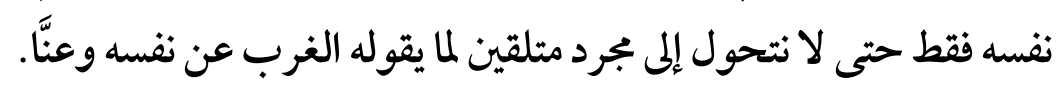

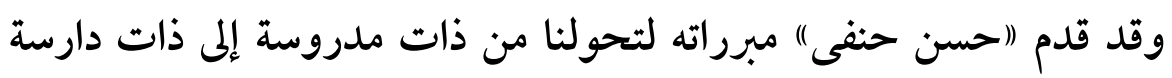

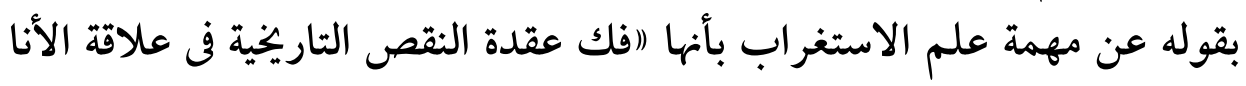

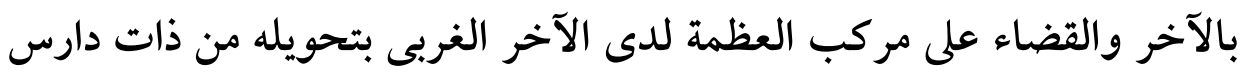

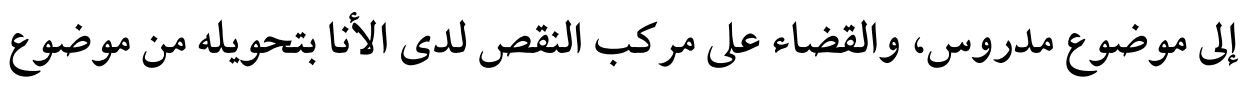

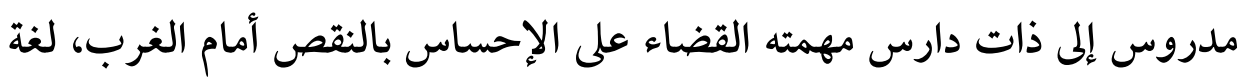
وثقافة وعلماً، مذاهباً ونظريات وآراء مُما يخلق فيهم إحساساً بالدونية).

ويقول فى موضوع آخر "(إن مهمة علم الاستغراب هى القضاء على المركزية

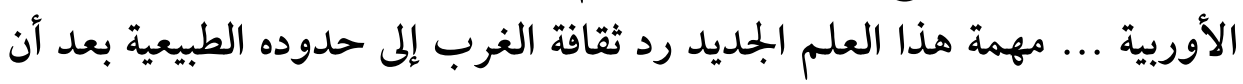

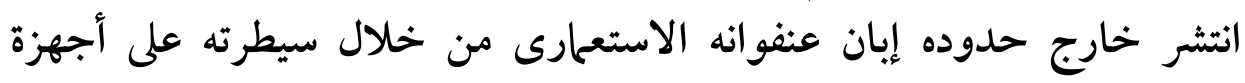

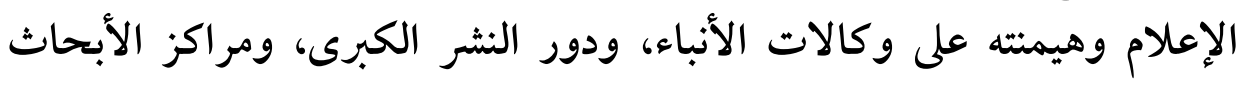
العلمية، والاستخبارات العامة ....1).

وقد تضمن الكتاب دراسات عميقة لتاريخ الفكر الأوربى مبتدئا بالحديث

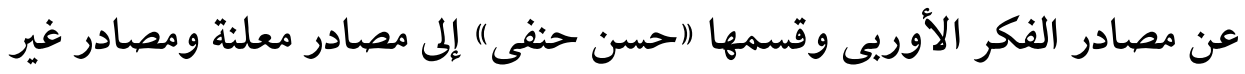




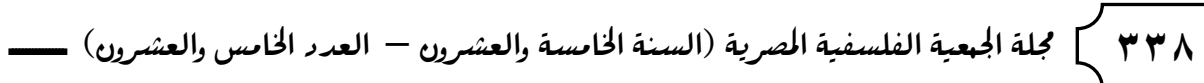

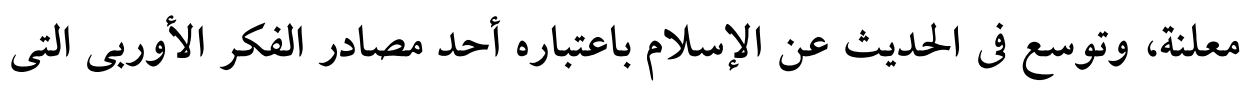

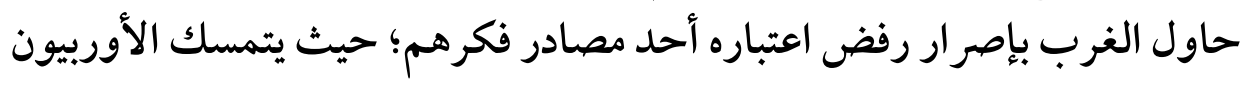

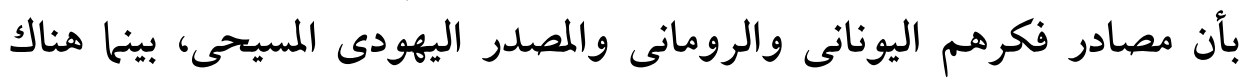
مصادر غير معلنة وهى المصدر الشرقى القديم، ويقصد به المصدر الإسلامى المئى

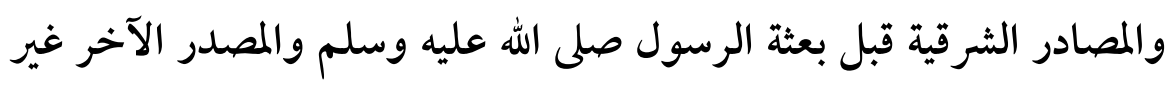
المعلن هو البيئة الأوربية نفسها.

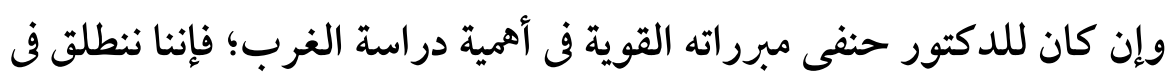

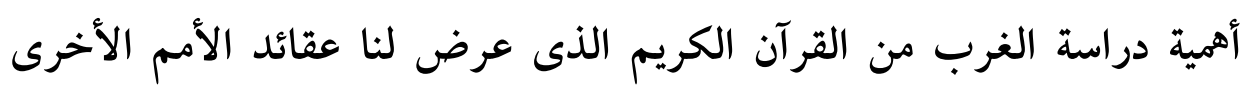

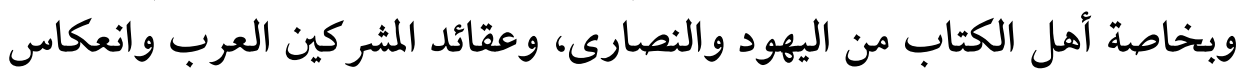
هذه العقائد على السلوك الاجتحاعى والاقتصادى والسياسى.

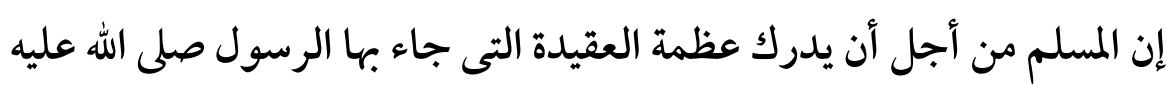

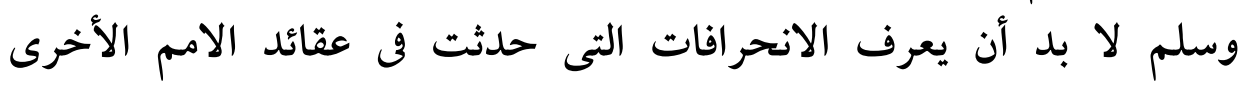
والانجر افات السلوكية المنبثة عن هذه العقائد. 


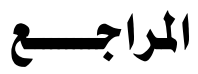

- ا.ج آربرى: المستشرقون البريطانيون، تعريب محمد الدسوقى (لندن. وليم كولتير،

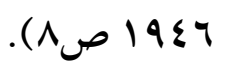

- ابوخليل: الإسقاط في مناهج المستشرقين والمثرقين-بيروت-دار الفكر$.1990 / 1 \leqslant 17$

- ابوزيد احمد: الهجوم على الإسلام فى الروايات الأدبية-مكة المكرمة-رابطة العالم

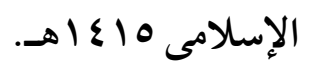

- احمد عبد الحميد غراب: رؤية إسلامية للاستشراق - طب (بيرمنجهام): المنتدى

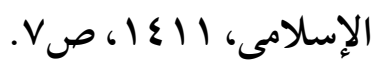

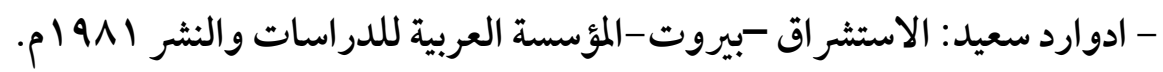
- أكرم ضياء العمرى: موقف الاستشراق من السيرة والسنة النبوية - الرياض - دار

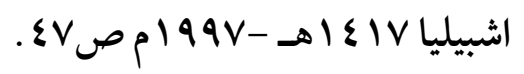

- السيد محمد الثاهد: (الاستشراق ومنهجية النقد عند المسلمين المعاصرين) في الاجتهاد

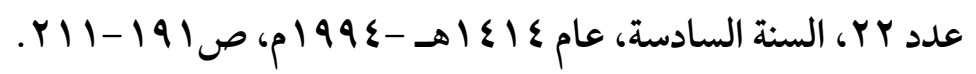

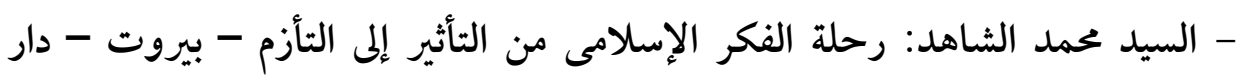

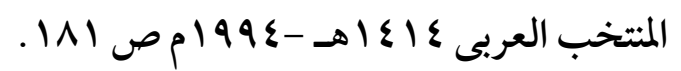

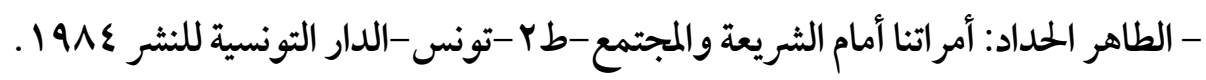

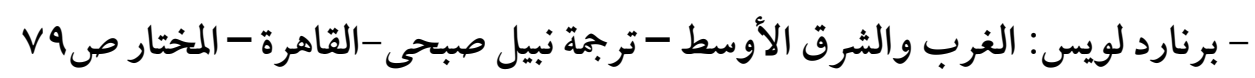

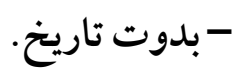

- رودى بارت: (الدراسات العربية والإسلامية فى الجامعات الألمانية) ترجمة مصطفى

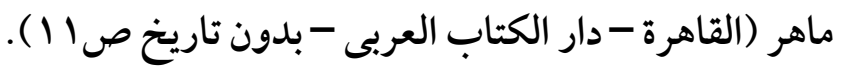
- عبد الرحمن العشماوى: وقفة مع جرجى زهره زيدان-الرياض-مكتبة العبيكان .1994/1 /

- عبد الرحمن بدوى: موسوعة المستشرقين - بيروت - دار العلم للملايين ع191

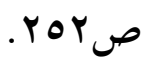




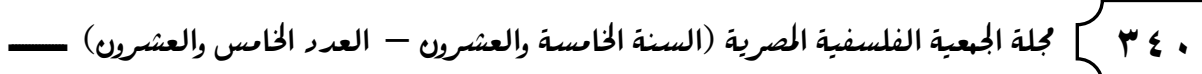

- عرفان عبد الحميد: المستشرقون والإسلام طب-بيروت-المكتب الإسلامى-

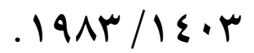

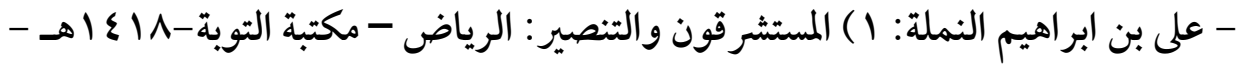

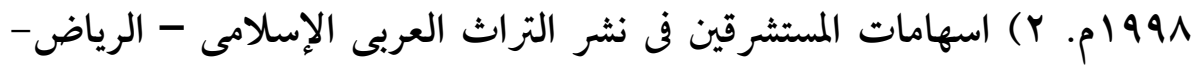

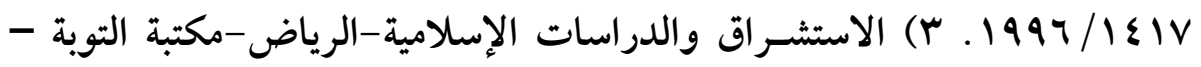

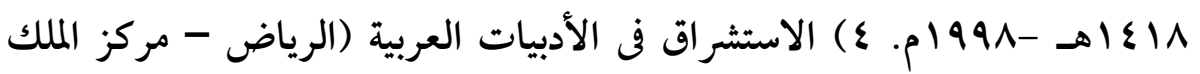

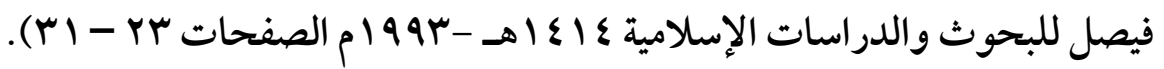
- محمد أحمد نظمى: موقف الاستشراق بين الفصحى والعامية في الاستشر اق-بغداد-دار

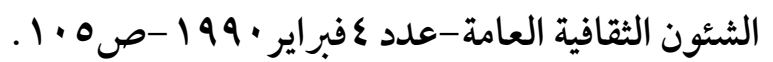

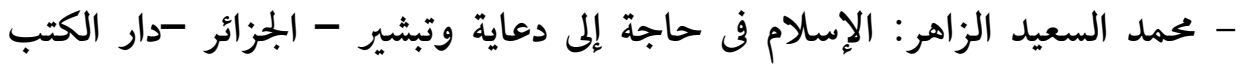

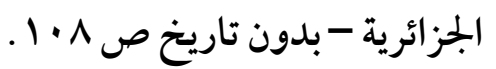

- محمد السيد الزاهر : الإسلام فى حاجة إلى دعاية وتبشير - الجزائر - دار الكتب الجزائرية

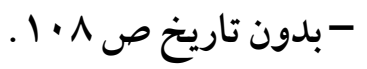

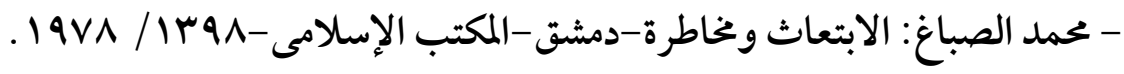
- محمد خليفة: آثار الفكر الاستشرافى فى المخرجات الإسلامية - القاهرة - عين

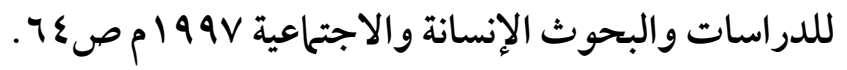
- محمد عطية خميس : مؤامرات ضد الأسرة المسلمة-القاهرة-بدوت ناشر -بدون تاريخ. - محمد عمارة: الغزو الفكرى، وهم أم حقيقة؟ القاهرة - دار الشروق 9 ـــاهـ| . 1919

- محمد قطب: واقعنا المعاصر (جدة - مؤسسة المينة المنورة للنشر والتوزيع V• ع عاهـ/ ا $19 \Lambda V$ - محمد محمد حسين: الإسلام والحضارة الغربية - طه-بيروت-مؤسسة الرسالة . $9194 /$ / $1 \varepsilon \cdot r$

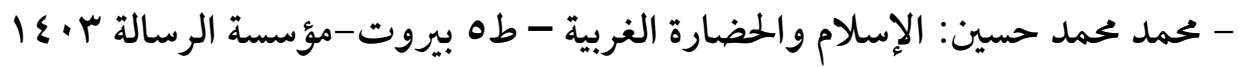
. 27 ص $191 Y-$ 
- محمود حمدى زقزوق: الاستشراق والخلفية الفكرية للصراع الحضارى - قطر وزارة

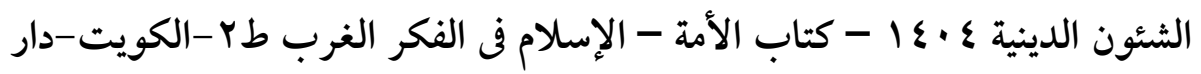

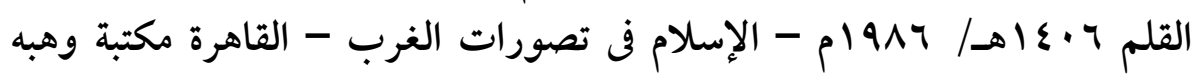

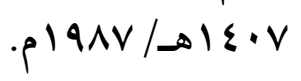
- محمود شاكر : (رسالة فى الطريق إلى ثقافتنا)، جدة - دار المدنى V • ع اهـ -

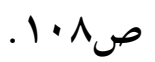
- مصطفى السباعى: السنة ومكانتها فى التشريع الإسلامى - بيروت - المكتبة الإسلامية

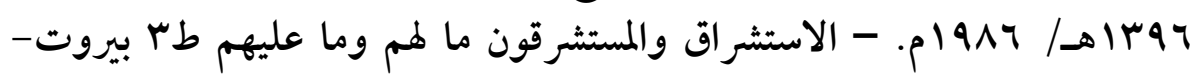

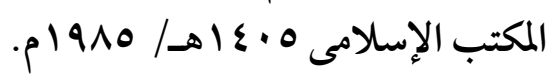
- مكسيم روبنسون: الصورة الغربية والدراسات الغربية الإسلامية فى تراث الإسلام

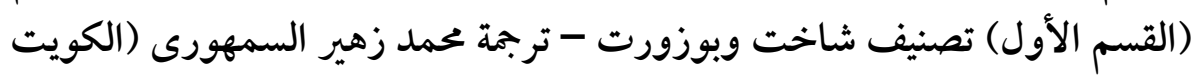

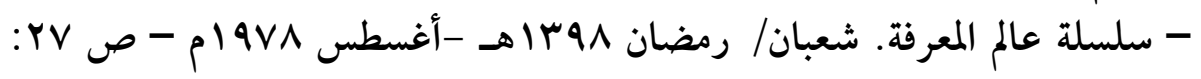
$(1 \cdot 1$ - نجيب العقيقى: المستشرقون-r أجزاء طع -القاهرة-دار المعارف-بدون تاريخ.

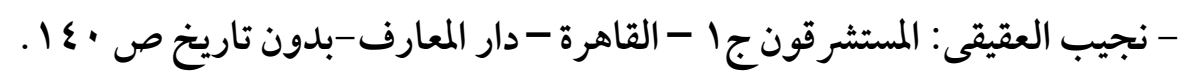

